\title{
Umbilicoplasty: Classification of surgical procedures and a modified technique for the everted umbilicus
}

\author{
Mohammed M Al-Qattan MB BS FRCSC, Abdul K El-Bakry FRCS \\ Divisions of Plastic and General Surgery, King Saud University, Riyadh, Saudi Arabia
}

MM Al-Qattan, AK El-Bakry. Umbilicoplasty: Classification of surgical procedures and a modified technique for the everted umbilicus. Can J Plast Surg 1996;4(3):172174. Umbilicoplasty is a term used to describe several surgical procedures of the umbilicus. A classification of umbilicoplasty procedures is offered, along with a modified technique for correcting the everted or protuberant umbilicus.

Key Words: Everted Unbilicus, Surgery, Umbilicoplasty

\section{Ombilicoplastie : classification des interventions chirurgicales et techniques modifiées pour l'éversion de l'ombilic}

RÉSUMÉ : Ombilicoplastie est le terme qui désigne diverses interventions chirurgicales à l'ombilic. Dans cet article, une classification des interventions d'ombilicoplastie est présentée, de même qu'une technique modifiée pour corriger l'éversion ou la protubérance de l'ombilic.

Umbilicoplasty or omphaloplasty is a term used by plastic and general surgeons to describe several different surgical procedures of the umbilicus. In this paper, a classification of umbilicoplasty procedures is offered, along with a modified technique for correcting the everted umbilicus.

The literature on umbilicoplasty was reviewed and the surgical procedures classified into four main categories: placing an existing umbilicus into a new position during abdominoplasty; converting an everted umbilicus into an inverted one; excising the umbilicus and immediate reconstruction; and delayed reconstruction of the umbilicus. Our modified technique for the everted umbilicus is also described with an illustrative case.

\section{REVIEW OF UMIBILICOPLASTY PROCEDURES}

The four main categories of umbilicoplasty procedures are summarized in Table 1. Placing of an existing umbilicus into a new position during abdominoplasty (1-4) should produce a natural appearing umbilicus and avoid a circular scar that may constrict or deform the navel area.

The everted or protuberant umbilicus may be seen with or without concurrent umbilical hernia. In the absence of a hernia, protuberance is caused by a mass of subcutaneous scar tissue which fills and obliterates the umbilical tube. Removal of the 
scar tissue and recreation of an inverted umbilicus with a superior hood is the treatment of choice (5). In the case of an everted umbilicus with concurrent umbilical hernia, simultaneous herniorrhaphy and umbilical reconstruction is performed. Takato et al (6) described a method in which an inferiorly based, reverse $U$ incision was made around the protruding umbilicus. Through this incision the fascial defect was closed, and the elevated U-shaped flap was then fixed to the rectus fascia recreating an inverted umbilicus. Apfelberg et al (7) created a superiorly based skin flap over the protruding umbilicus. After hernia repair, the surrounding skin was cut out in a batwing fashion to enlarge the area, and the skin flap was stretched in all directions to cover the protruding umbilicus. However, some umbilical protuberance persisted and the final result seemed less than optimal (7).

TABLE 1: Four main categories of umbilicoplasty procedures
Umbilicoplasty procedure
Placing an existing umbilicus into a new position during abdominoplasty
Conversion of an everted umbilicus into an inverted umbilicus
$\begin{array}{lc}\text { a) in absence of concurrent umbilical hernia } & 1-4 \\ \text { b) in presence of concurrent umbilical hernia } & 5 \\ \text { Excision of the umbilicus and immediate reconstruction } & \text { present study } \\ \text { Delayed reconstruction of the umbilicus } & 8-10 \\ \text { a) with simultaneous abdominoplasty } & \\ \text { b) without abdominoplasty } & 1,3,7,11,12 \\ \end{array}$

\section{CASE PRESENTATION}

A patient with a large peri-umbilical hernia and an everted umbilicus presented to the authors (Figure 1). It was decided that Takato's technique was not suitable for this patient, not only because the fascial defect was large and required wider exposure, but also because the excessive amount of hyperpigmented skin of the protruding umbilicus required skin resection. An inferior peri-umbilical incision with lateral extensions was made. This incision allowed wide exposure, and the fascial defect was closed. The inferior part of the hyperpigmented umbilical skin was resected, and the umbilicus was fixed to the rectus fascia with polypropylene sutures (Figure 2). A pressure dressing was used along with an abdominal binder postoperatively. The patient was pleased with the final appearance of the new umbilicus (Figure 3). 


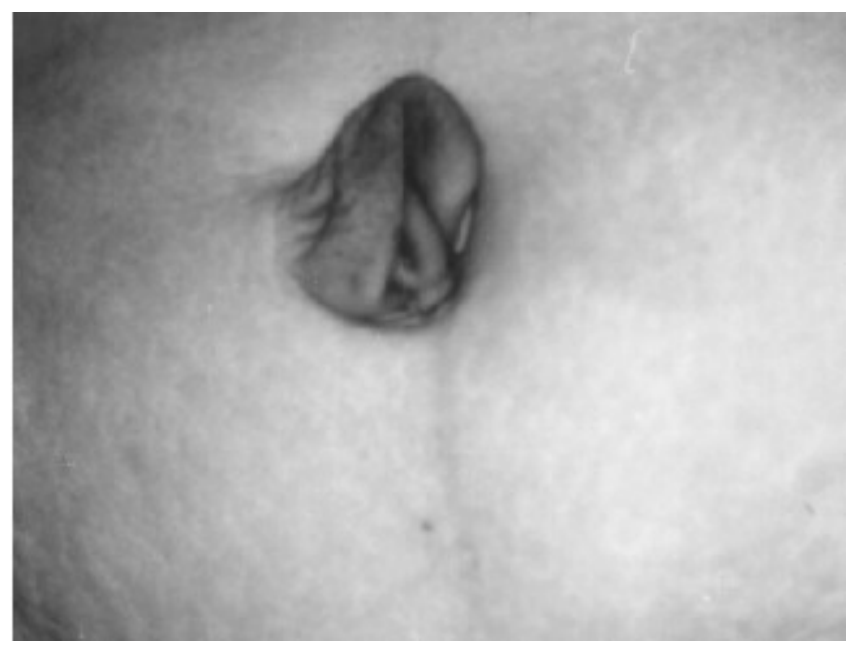

Figure 1) A 40-year-old female with an everted umbilicus caused by a large periumbilical hernia. Note the excessive amount of hyperpigmented skin of the protruding umbilicus

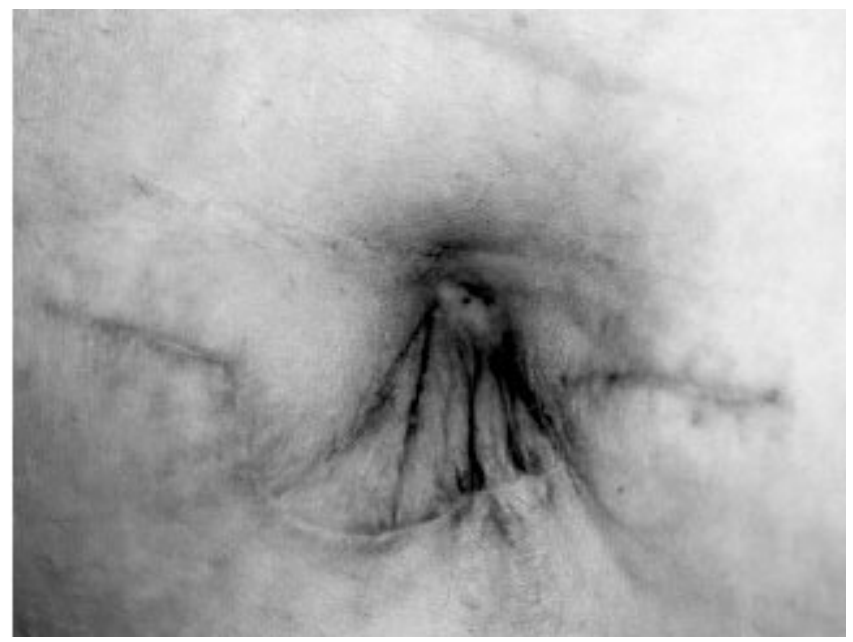

Figure 2) Immediate postoperative picture. Note the inferior peri-umbilical incision with lateral extensions. The inferior part of the hyperpigmented umbilical skin was resected before final closure 


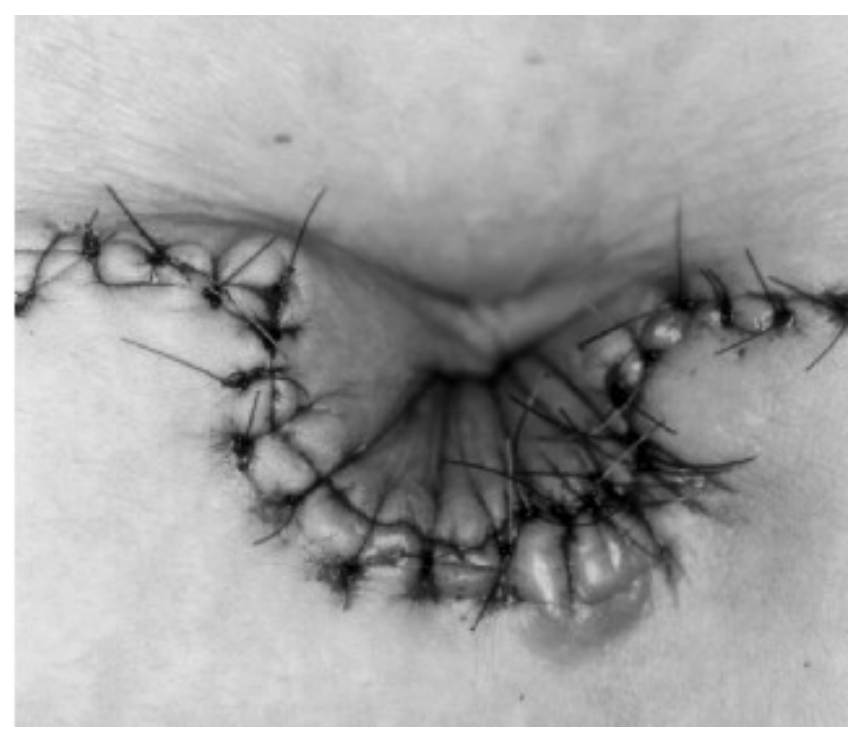

Figure 3) New umbilicus six months after surgery

\section{DISCUSSION}

Indications for excision of the umbilicus are rare and include tumours, keloids and urachal fistulae. Immediate reconstruction of the umbilicus can be performed using local skin flaps with or without skin grafts (8-10).

Delayed reconstruction of the umbilicus with simultaneous abdominoplasty has been described $(1,3,7,11,12)$. Baroudi $(1,3)$ prefers to resect the old navel site and the excess lower abdominal dermo-fat flap. The selected site for the umbilicus is then defatted and a new navel is created by four cardinal sutures fixing the dermis to the rectus fasica. On the other hand, Guerrerosantos et al (11) and Apfelberg et al (7) prefer to isolate a circular island of skin and subcutaneous tissue (left attached to the rectus fascia) before undermining of the abdominal skin. This island of skin is exteriorized as the new umbilicus at the completion of the abdominoplasty procedure.

Several techniques of delayed umbilical reconstruction without simultaneous abdominoplasty have been described. Examples of such techniques include the quadrilateral skin excisions of Borges (13), Y incision method of Kirianoff (14), the double V-Y procedure of Jamra (15), the conchal cartilage graft technique of Matsuo et al (16), the cone flap of Itoh and Arai (17) and the circular island-purse string method of Marconi (18).

\section{CONCLUSION}

The navel is the only scar that is considered natural and aesthetic (1). Absence or deformity of the umbilicus is distressing and may be a source of embarrassment. Reconstruction of a normal looking umbilicus with a superior hood and without stenosis is a challenge. This explains the large number of different umbilicoplasty procedures 
described in the literature. It is hoped that the classification of such procedures will help doctors select the appropriate reconstructive technique.

\section{REFERENCES}

1. Baroudi R. Umbilicoplasty. Clin Plast Surg 1975;2:431-48.

2. Juri J, Juri C, Raiden G. Reconstruction of the umbilicus in abdominoplasty. Plast Reconstr Surg 1979;63:580-2.

3. Baroudi R. Body Sculpturing. Clin Plast Surg 1984;11:419-43.

4. Ribeiro L, Muzy S, Accorsi A. Omphaloplasty. Ann Plast Surg 1991;27:457-75.

5. Hodgkinson DJ. Umbilicoplasty: Conversion of 'outie' to 'innie'. Aesthetic Plast Surg 1983;7:221-2.

6. Takato T, Itoh M, Kamei M, Uchiyama K. Our method of umbilical reconstruction. Jpn J Plast Reconstr Surg 1989;32:133-6.

7. Apfelberg DB, Maser MR, Lash H. Two unusual umbilicoplasties. Plast Reconstr Surg 1979;64:268-70.

8. Ohjimi H, Nakamura M, Yasutomi Y. Reconstruction of an umbilicus. Jpn Plast Reconstr Surg 1989;32:357-61.

9. Ford T, Widgerow AD. Umbilical keloid: An early start. Ann Plast Surg 1990;25:2145.

10. Miller MJ, Balch CM. Iris technique for immediate umbilical reconstruction. Plast Reconstr Surg 1993;92:754-6.

11. Guerrerosantos J, Dicksheet S, Carrillo C, Sandoval M. Umbilical reconstruction with secondary abdominoplasty. Ann Plast Surg 1980;5:139-44.

12. de Lacerda DJC, Martins DMFS, Marques A, Brenda E, de Moura Andrews Jr.

Umbilicoplasty for the abdomen with a thin adipose layer. Br J Plast Surg 1994;47:386-7.

13. Borges AF. Reconstruction of the umbilicus. Br J Plast Surg 1975;28:75-6.

14. Kirianoff TG. Making a new umbilicus when none exists. Case report. Plast Reconstr Surg 1978;61:603-4.

15. Jamra FA. Reconstruction of the umbilicus by a double V-Y procedure. Plast Reconstr Surg 1979;64:106-7.

16. Matsuo K, Kondoh S, Hirose T. A simple technique for reconstruction of the umbilicus, using a conchal cartilage composite graft. Plast Reconstr Surg 1990;86:14951.

17. Itoh Y, Arai K. Umbilical reconstruction using a cone-shaped flap. Ann Plast Surg 1992;28:335-8.

18. Marconi F. Reconstruction of the umbilicus: A simple technique. Plast Reconstr Surg 1995;95:1115-7. 